\title{
Evaluation of the promoter region polymorphism (5-HTTLPR) in the serotonin transporter gene in females with postpartum depression
}

\author{
XIAOLI ZHANG ${ }^{1}$, LIN WANG $^{2}$, FENGHUA HUANG $^{1}$, JIAFU LI $^{1}$, LI XIONG $^{3}$, \\ $\mathrm{HAN} \mathrm{XUE}^{4}$ and YUANZHEN ZHANG ${ }^{1}$ \\ ${ }^{1}$ Department of Obstetrics and Gynecology, Zhongnan Hospital of Wuhan University; \\ ${ }^{2}$ Department of Histology and Embryology, Medical College of Wuhan University; \\ Departments of ${ }^{3}$ Neurology and ${ }^{4}$ Clinical Laboratory, Zhongnan Hospital of Wuhan University, \\ Wuhan, Hubei 430071, P.R. China
}

Received March 18, 2014; Accepted October 2, 2014

DOI: $10.3892 /$ etm.2014.2043

\begin{abstract}
The aim of the present study was to investigate the association between polymorphism in the serotonin transporter (5-HTT) gene-linked polymorphic region (5-HTTLPR) in the promoter region of the 5-HTT gene and the pathogenesis of postpartum depression (PPD). Blood samples were collected from 120 female patients with PPD and 140 age-matched normal controls. Polymerase chain reaction analysis was performed to detect the 5-HTTLPR polymorphism in these subjects, and the genotype and allele frequencies were compared between the two groups. The disease severity was evaluated using the Hamilton Depression Rating Scale (HAMD) score. The results showed that the frequency of the homozygous long/long $(\mathrm{L} / \mathrm{L})$ genotype was significantly lower in the PPD group than that in the control group; by contrast, the frequencies of the heterozygous long/short (L/S) and homozygous S/S genotypes were similar for the two groups, without significant differences. No significant differences were observed in the $\mathrm{L}$ and $\mathrm{S}$ allele frequencies between the two groups. Furthermore, compared with the L/S heterozygous and S/S homozygous genotypes, patients with PPD with the L/L homozygous genotype had a significantly lower HAMD score. The present results suggest that female patients with PPD carrying the homozygous L/L genotype may be less susceptible to depressive symptoms and that the $\mathrm{L} / \mathrm{L}$ genotype may be associated with the reduced occurrence of PPD. These findings provide a theoretical basis for the clinical diagnosis and treatment of PPD.
\end{abstract}

Correspondence to: Professor Yuanzhen Zhang, Department of Obstetrics and Gynecology, Zhongnan Hospital of Wuhan University, 169 Donghu Road, Wuhan, Hubei 430071, P.R. China E-mail: gxfc55@163.com

Key words: postpartum depression, 5-HTTLPR, serotonin transporter, gene polymorphism

\section{Introduction}

Postpartum depression (PPD) is a mood disorder in females that usually presents within the first 4-6 weeks after childbirth; the condition is clinically characterized by depression, sadness, frustration, crying, irritability, restlessness and even suicidal tendencies (1). According to a previous meta-analysis, PPD is prevalent worldwide, and $10-15 \%$ of females may be affected (2). In addition to the general symptoms of depression, PPD can, in certain cases, be associated with a disturbance of consciousness, psychotic symptoms and Schneider's symptoms, which can only be alleviated by regular treatments $(3,4)$. It has been acknowledged that PPD is induced by biological, psychological and/or social factors; bio-genetics in particular is closely linked with the mental illnesses $(5,6)$.

Recent genetic studies have shown that dysfunction of the 5-hydroxytryptamine (5-HT) system is the key factor in the development of depression (7,8). Accordingly, genes associated with the synthesis, release, uptake and metabolism of 5-HT could become candidates for studies on the pathogenesis of depression. The serotonin transporter (5-HTT) plays an important role in the re-uptake of 5-HT following release, and therefore is the target for the majority of antidepressants $(9,10)$. A recent study indicated that the transcriptional activity of the human 5-HTT gene is regulated by the 5-HTT gene-linked polymorphic region (5-HTTLPR) (11), with long (L) and short (S) alleles. The L allele in 5-HTTLPR is associated with higher transcriptional efficiency of the promoter compared with the $\mathrm{S}$ allele. The mRNA transcription and protein expression levels of 5-HTT are higher in individuals with a homozygous $\mathrm{L} / \mathrm{L}$ genotype than those with S/S genotypes (12).

To date, the association between 5-HTTLPR gene polymorphism and PPD has not been fully established, and there are few studies focusing on the association between the genetic polymorphism and the clinical characteristics. In the present study, the 5-HTTLPR status in the 5-HTT gene was evaluated in order to establish whether it had an association with PPD pathogenesis in Han female patients. 


\section{Materials and methods}

Patients. A total of 120 Han female patients with PPD, aged 20-35 years (mean age, $28.57 \pm 6.8$ years), with a course of disease ranging between six weeks and six months, were enrolled in the present study. The patients had all been admitted to the Zhongnan Hospital of Wuhan University (Wuhan, China) between 2008 and 2012. The patients had been diagnosed with PPD according to the diagnostic criteria for depression (for PPD, occurring within 6 months after delivery) from the Chinese Classification of Mental Disorders (13), as well as the Hamilton Depression Rating Scale (HAMD) score (24-item version). An additional 140 Han females with similar social background were included as normal controls, aged 20-35 years (mean age, $26.18 \pm 7.2$ years). None of the subjects or their parents were involved in drug abuse and/or addiction, nor had a history of mental illness, serious physical illness or organic brain diseases. Prior written and informed consent was obtained from every patient and the study was approved by the Ethics Review Board of the Zhongnan Hospital of Wuhan University.

Blood sample collection. Peripheral blood samples from the subjects in the PPD and control groups were collected under fasting conditions in the morning. A total of $100 \mu 1$ EDTA $(0.5 \mathrm{~mol} / 1 ; \mathrm{pH} 8.0)$ was added for anticoagulation, and these blood samples were stored at $-80^{\circ} \mathrm{C}$ until use.

DNA extraction and polymerase chain reaction $(P C R)$ analysis. Genomic DNA was extracted using a whole blood genomic DNA extraction kit (Qiagen $\mathrm{GmbH}$, Hilden, Germany), according to the manufacturer's instructions, and then analyzed with $0.8 \%$ agarose gel electrophoresis. Amplification primers for the promoter region of the 5-HTT gene were as follows: Forward primer, 5'-GCGCTCCTGCATCCCCCATTA-3'; and reverse primer, 5'-GGGATGCGGGGGAATACTGGT-3'. 5-HTTLPR polymorphism in the 5-HTT promoter region was assessed using PCR amplification. A total of $25 \mu$ PCR reaction solution was prepared by mixing 10X PCR reaction buffer [containing $2.0 \mathrm{mmol} / \mathrm{l}\left(\mathrm{NH}_{4}\right)_{2} \mathrm{SO}_{4}$ and $\mathrm{MgCl}_{2}$; Invitrogen Life Technologies, Carlsbad, CA, USA], $0.16 \mu \mathrm{mol} / 1$ each primer, 1.5 units Taq enzymes and $160 \mu \mathrm{mol} / 1$ deoxyribonucleotide triphosphates. The PCR conditions were as follows: Denaturation at $95^{\circ} \mathrm{C}$ for $2 \mathrm{~min}$, followed by 35 cycles of $95^{\circ} \mathrm{C}$ for $60 \mathrm{sec}, 62^{\circ} \mathrm{C}$ for $60 \mathrm{sec}$ and $72^{\circ} \mathrm{C}$ for $60 \mathrm{sec}$, and then extension at $72^{\circ} \mathrm{C}$ for $10 \mathrm{~min}$. The PCR products were separated by $2 \%$ agarose gel electrophoresis, and the gel was visualized and analyzed by a Bio-Rad image analysis system (Bio-Rad, Hercules, CA, USA). Two different allelic fragments with the lengths of $297 \mathrm{bp}(\mathrm{L})$ and $253 \mathrm{bp}(\mathrm{S})$ were detected among the PCR products, and the genotype was determined accordingly (Fig. 1) (14).

Statistical analysis. Statistical analysis was performed using SPSS 13.0 software (SPSS, Inc., Chicago, IL, USA). A $\chi^{2}$ test of goodness of fit was used to test the Hardy-Weinberg $(\mathrm{H}-\mathrm{W})$ equilibrium in the samples. $\mathrm{P}<0.05$ was considered to indicate a statistically significant difference.
Table I. Hardy-Weinberg equilibrium test of the 5-HTTLPR genotype distribution in the PPD and control groups.

\begin{tabular}{lccccc}
\hline Group & Genotype & $\begin{array}{c}\text { Observed } \\
\text { value }\end{array}$ & $\begin{array}{c}\text { Expected } \\
\text { value }\end{array}$ & $\chi^{2}$ & P-value \\
\hline PPD & L/L & 5 & 6.51 & & \\
& L/S & 46 & 42.89 & & \\
& S/S & 69 & 70.59 & 0.612 & $>0.05$ \\
Control & L/L & 19 & 12.90 & & \\
& L/S & 47 & 59.09 & & \\
& S/S & 74 & 67.90 & 2.884 & $>0.05$ \\
\hline
\end{tabular}

PPD, postpartum depression; L, long; S, short.

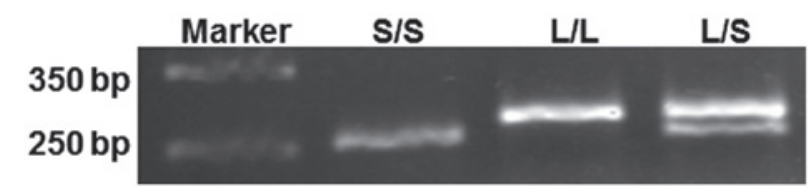

Figure 1. Genotype analysis of 5-HTTLPR polymorphism in the 5-hydroxytryptamine transporter promoter region with polymerase chain reaction amplification. L, long; S, short.

\section{Results}

$H$-W equilibrium test of the 5-HTTLPR genotype distribution. To investigate the representativeness of the samples, the H-W equilibrium, with the respect to the 5-HTTLPR polymorphism, was examined in the population of the PDD and control groups. The results showed that the genotype frequency distribution of the 5-HTTLPR polymorphism in the enrolled population was in $\mathrm{H}-\mathrm{W}$ equilibrium, and no significant differences were found between the observed and expected values $(\mathrm{P}>0.05)$ (Table I). These results suggest that the enrolled population was a good representative sample.

Comparison of 5-HTTLPR polymorphism genotype distribution between the PPD and control groups. To investigate the association between 5-HTTLPR gene polymorphism and PPD, the genotype frequencies were examined and compared between the PPD and control groups. The results showed that the frequency of the homozygous L/L genotype was significantly lower in the PPD group (4.17\%) than that in the control group (15.83\%) $\left(\chi^{2}, 6.854 ; \mathrm{P}=0.032\right)$. By contrast, the frequencies of the heterozygous $\mathrm{L} / \mathrm{S}$ and homozygous $\mathrm{S} / \mathrm{S}$ genotypes were similar in the two groups, without significant differences (Table II and Fig. 2). In addition, no significant differences in the frequencies of the $\mathrm{L}$ and $\mathrm{S}$ alleles were found between the PPD and control groups $\left(\chi^{2}, 3.226\right.$; $\mathrm{P}=0.072$ ) (Table III and Fig. 3). These results suggest that the L/L homozygous genotype may be associated with the reduced occurrence of PPD.

Association between 5-HTTLPR polymorphism genotype and HAMD score in PPD. To further investigate the role of the 5-HTTLPR polymorphism genotypes in PPD, the disease 
Table II. Comparison of the 5-HTTLPR genotype frequencies between the PPD and control groups.

\begin{tabular}{lcrcc}
\hline & & \multicolumn{3}{c}{ 5-HTTLPR genotype frequencies } \\
\cline { 3 - 5 } Group & $\mathrm{N}$ & $\mathrm{L} / \mathrm{L}, \%(\mathrm{n})$ & $\mathrm{L} / \mathrm{S}, \%(\mathrm{n})$ & $\mathrm{S} / \mathrm{S}, \%(\mathrm{n})$ \\
\hline PPD & 120 & $4.17(5)^{\mathrm{a}}$ & $38.33(46)$ & $57.50(69)$ \\
Control & 140 & $15.83(19)$ & $39.17(47)$ & $52.86(74)$ \\
Total & 260 & $9.23(24)$ & $35.77(93)$ & $55.00(143)$ \\
\hline
\end{tabular}

${ }^{a}$ Compared with the control group, $\chi^{2}=6.854$ and $\mathrm{P}=0.032$. PPD, postpartum depression; L, long; S, short.

Table III. Comparison of the 5-HTTLPR allele frequencies between the PPD and control groups.

\begin{tabular}{lllc}
\hline & & \multicolumn{2}{c}{ 5-HTTLPR allele frequencies } \\
\cline { 3 - 4 } Group & $\mathrm{N}$ & $\mathrm{L}, \%(\mathrm{n})$ & $\mathrm{S}, \%(\mathrm{n})$ \\
\hline PPD & 240 & $23.33(56)$ & $76.67(184)$ \\
Control & 280 & $30.36(85)$ & $69.64(195)$ \\
Total & 520 & $27.12(141)$ & $72.88(379)$ \\
\hline
\end{tabular}

No significant differences were found in the frequencies of the $\mathrm{L}$ and $S$ alleles between the PPD and control groups $\left(\chi^{2}=3.226\right.$ and $\mathrm{P}=0.072$ ). $\mathrm{PPD}$, postpartum depression; $\mathrm{L}$, long; $\mathrm{S}$, short.

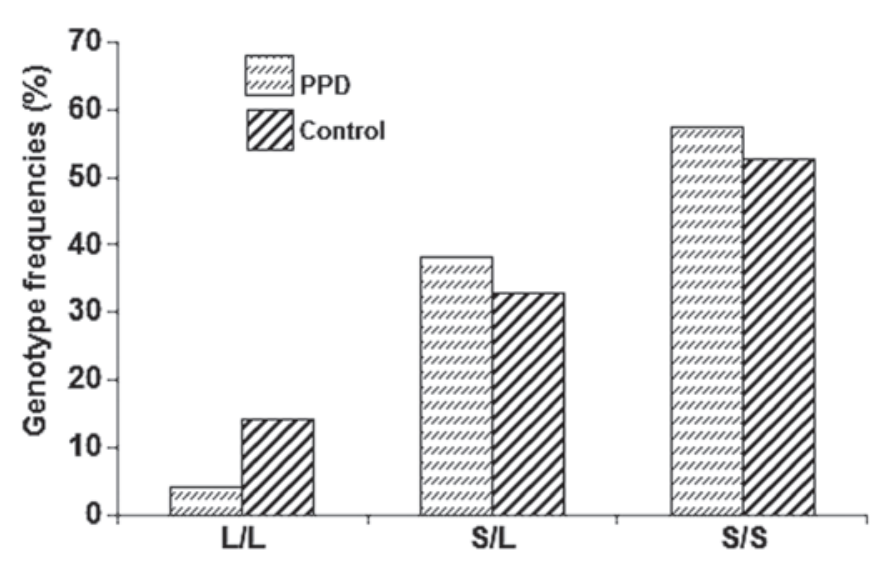

Figure 2. Comparison of the 5-HTTLPR genotype frequencies between the PPD and control groups. The frequency of the L/L genotype was significantly lower in the PPD group than that in the control group, while the frequencies of the $\mathrm{L} / \mathrm{S}$ and $\mathrm{S} / \mathrm{S}$ genotypes were similar for these two groups. PPD, postpartum depression; L, long; S, short.

severity was evaluated using the HAMD score. The results showed that, compared with the L/S heterozygous and S/S homozygous genotypes, patients with PPD carrying the L/L homozygous genotype had a significantly lower HAMD score $(\mathrm{P}<0.001)$ (Table IV). These results suggest that homozygous L/L carriers with PPD may be less susceptible to the depressive symptoms.
Table IV. HAMD scores for patients with postpartum depression with different genotypes.

\begin{tabular}{lrrcr}
\hline Genotype & N & HAMD score & F & P-value \\
\hline L/L & 5 & $27.8 \pm 2.39$ & 78.33 & $<0.001$ \\
L/S & 46 & $41.4 \pm 2.26$ & & \\
S/S & 69 & $45.4 \pm 3.39$ & & \\
\hline
\end{tabular}

HAMD, Hamilton Depression Rating Scale; L, long; S, short.

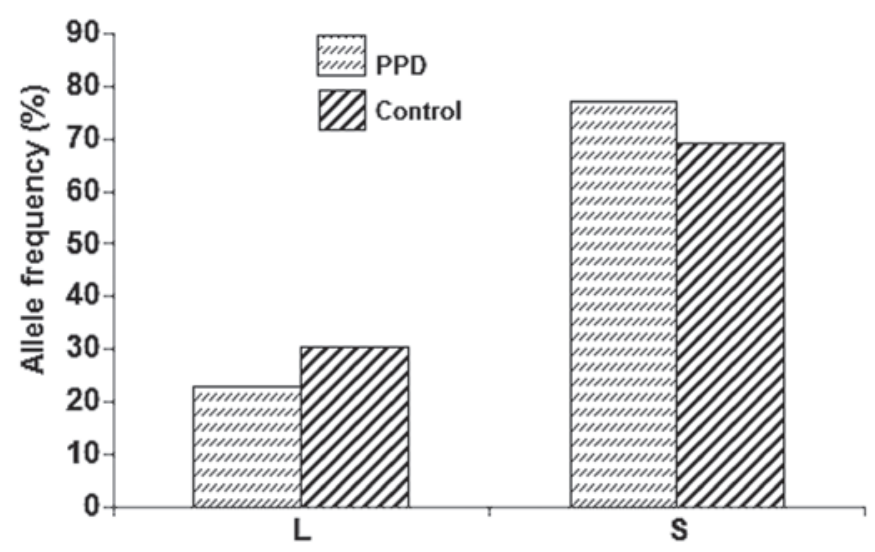

Figure 3. Comparison of the 5-HTTLPR allele frequencies between the PPD and control groups. No significant differences were observed in the $\mathrm{L}$ and $\mathrm{S}$ allele frequencies between the PPD and control groups. PPD, postpartum depression; L, long; S, short.

\section{Discussion}

PPD was first described by Pitt in 1968 (15). Epidemiological studies show that patients with PPD often exhibit seriously depressed mood following delivery, including various psychotic and mood disorders $(16,17$. PPD jeopardizes the physical and mental health of the parturient females, as well as their infants. Under certain circumstances, postpartum psychosis can also be induced, causing a substantial economic burden for families and society. The pathophysiology of PPD is complex, and the mechanism is still yet to be thoroughly clarified. It is believed that the pathogenesis and development of PPD involve a variety of internal and external factors (18).

In recent years, with the rapid development of human genomics studies, attempts have been made to elucidate the association between genetic polymorphisms and PPD susceptibility $(19,20)$. It has been shown that the neurotransmitter 5 -HT is involved in regulating a number of physical and mental activities, and plays an important role in the pathogenesis of depression (21-22). Furthermore, the re-uptake of 5-HT is regulated by the 5-HTT, which is widely distributed on the presynaptic membranes in the central nervous system (24). Pre-clinical and clinical studies have therefore focused on this target for the treatment of depression $(25,26)$.

The human 5-HTT gene (also known as SLC6A4) is located on chromosome 17q11.1-q12 and contains 14 exons. The 5-HTT gene-linked polymorphic region (5-HTTLPR) has been recognized as one of the functional polymorphism sites 
of the 5-HTT gene (27). There are three genotypes, L/L, L/S and $\mathrm{S} / \mathrm{S}$, for 5-HTTLPR polymorphism. A number of studies have shown that the $\mathrm{S}$ allele could be the susceptible factor for depression, while the genotype of $\mathrm{L} / \mathrm{L}$ would be protective against depression (28-30). By contrast, other studies have revealed that the frequency of the $\mathrm{L}$ allele in patients with depression is considerably higher than that in the control group, indicating an association between the $\mathrm{L}$ allele and the pathogenesis of depression $(31,32)$. Other studies, however, have speculated that 5-HTTLPR is not associated with depression, or at least is not the major risk factor (33-37).

In the present study, it was found that the $\mathrm{L}$ and $\mathrm{S}$ allele frequencies in Han female patients with PPD were similar to those in normal controls. The $\mathrm{S}$ allele was predominant in normal Han females (69.64\%), with the S/S genotype accounting for $52.86 \%$ and the $\mathrm{L} / \mathrm{L}$ genotype for $15.83 \%$ of the genotypes in the group. This was consistent with previous studies concerning the genotype distribution and allele frequencies in the Han population $(38,39)$. Notably, the present results indicated that the frequency of the L/L homozygous genotype was significantly lower in the patients with PPD (4.17\%) than that in the normal control females (15.83\%). In addition, the HAMD score from the patients with PPD with the L/L homozygous genotype $(27.8 \pm 2.39)$ was markedly lower than that either from the L/S $(41.4 \pm 2.26)$ or the $\mathrm{S} / \mathrm{S}(45.4 \pm 3.39)$ carriers, indicating less severe depressive symptoms. These results suggest that the $\mathrm{L} / \mathrm{L}$ homozygous genotype could exert protective effects against the onset and development of PPD, reducing the susceptibility of patients to the disease.

In conclusion, the present results revealed the association between the 5-HTTLPR polymorphism and the pathogenesis of PPD in the Han population. Specifically, it was shown that the $\mathrm{L}$ allele in 5-HTTLPR was associated with a reduced susceptibility to PPD. These findings provide a theoretical basis for the clinical diagnosis and treatment of PPD. Due to the limited sample size of the present study, further studies with expanded samples are still required to validate the present results and to fully address the role of 5-HTTLPR polymorphism in PPD.

\section{Acknowledgements}

This study was supported by the Natural Science Foundation of Hubei Province (no. 2012FFB04430).

\section{References}

1. O'Hara MW and McCabe JE: Postpartum depression: current status and future directions. Annu Rev Clin Psychol 9: 379-407, 2013.

2. Paulson JF and Bazemore SD: Prenatal and postpartum depression in fathers and its association with maternal depression: a meta-analysis. JAMA 303: 1961-1969, 2010.

3. Fitelson E, Kim S, Baker AS and Leight K: Treatment of postpartum depression: clinical, psychological and pharmacological options. Int J Womens Health 3: 1-14, 2010.

4. O'Keane V, Lightman S, Patrick K, et al: Changes in the maternal hypothalamic-pituitary-adrenal ax is during the early puerperium may be related to the postpartum 'blues'. J Neuroendocrinol 23: $1149-1155,2011$.

5. Skalkidou A, Hellgren C, Comasco E, Sylvén S and Sundström Poromaa I: Biological aspects of postpartum depression. Womens Health (LondEngl) 8: 659-672, 2012.
6. Vliegen N, Casalin S and Luyten P: The course of postpartum depression: a review of longitudinal studies. Harv Rev Psychiatry 22: 1-22, 2014.

7. Maes M, Ringel K, Kubera M, Berk M and Rybakowski J: Increased autoimmune activity against 5-HT: a key component of depression that is associated with inflammation and activation of cell-mediated immunity, and with severity and staging of depression. J Affect Disord 136: 386-392, 2012.

8. Maes M, Leonard BE, Myint AM, Kubera M and Verkerk R: The new '5-HT' hypothesis of depression: cell-mediated immune activation induces indoleamine 2,3-dioxygenase, which leads to lower plasma tryptophan and an increased synthesis of detrimental tryptophan catabolites (TRYCATs), both of which contribute to the onset of depression. Prog Neuropsychopharmacol Biol Psychiatry 35: 702-721, 2011.

9. Lee S, Jeong J, Kwak Y and Park SK: Depression research: where are we now? Mol Brain 3: 8, 2010.

10. Pitychoutis PM, Dalla C, Sideris AC, Tsonis PA and Papadopoulou-Daifoti Z: 5-HT(1A), 5-HT(2A), and 5-HT(2C) receptor mRNA modulation by antidepressant treatment in the chronic mild stress model of depression: sex differences exposed. Neuroscience 210: 152-167, 2012.

11. Stephens MA, McCaul ME, Weerts EM and Wand G: Serotonin transporter-linked polymorphic region (5-HTTLPR) genotype is associated with cortisol responsivity to naloxone challenge. Psychopharmacology (Berl) 224: 223-230, 2012.

12. Heils A, Teufel A, Petri S, et al: Allelic variation of human serotonin transporter gene expression. J Neurochem 66: 2621-2624, 1996.

13. Dai Y, Yu X, Xiao Z, et al: Comparison of Chinese and international psychiatrists' views on classification of mental disorders. Asia Pac Psychiatry 6: 267-273, 2014.

14. Zimmermann-Peruzatto JM, Almeida S, Lucion AB, et al: Evaluation of the 5-HTTLPR and 5 -HTTVNTR polymorphisms in the serotonin transporter gene in women with postpartum depression. Neurosci Med 3: 275-280, 2012.

15. Pitt B: "Atypical" depression following childbirth. Br J Psychiatry 114: 1325-1335, 1968.

16. Mohammed ES, Mosalem FA, Mahfouz EM and Abd ElHameed MA: Predictors of postpartumdepression among rural women in Minia, Egypt: an epidemiological study. Public Health 128: 817-824, 2014.

17. Ayuso-Mateos JL, Vázquez-Barquero JL, Dowrick C, et al: Depressive disorders in Europe: prevalence figures from the ODIN study. Br J Psychiatry 179: 308-316, 2001.

18. Bener A, Burgut FT, Ghuloum S and Sheikh J. A study of postpartum depression in a fast developing country: prevalence and related factors. Int J Psychiatry 43: 325-337, 2012.

19. Mitchell C, Notterman D, Brooks-Gunn J, et al: Role of mother's genes and environment in postpartum depression. Proc Natl Acad Sci USA 108: 8189-8193, 2011.

20. Pinheiro RT, Coelho FM, Silva RA, et al: Association of a serotonin transporter gene polymorphism (5-HTTLPR) and stressful life events with postpartum depressive symptoms: a population-based study. J Psychosom Obstet Gynaecol 34: 29-33, 2013.

21. Kuzelova H, Ptacek R and Macek M: The serotonin transporter gene (5-HTT) variant and psychiatric disorders: review of current literature. Neuro Endocrinol Lett 31: 4-10, 2010.

22. Domínguez-López S, Howell R and Gobbi G: Characterization of serotonin neurotransmission in knockout mice: implications for major depression. Rev Neurosci 23: 429-443, 2012.

23. Sharp T and Cowen PJ: 5-HT and depression: is the glass half-full? Curr Opin Pharmacol 11: 45-51, 2011.

24. Landén M and Thase ME: A model to explain the therapeutic effects of serotonin reuptake inhibitors: the role of 5-HT2 receptors. Psychopharmacol Bull 39: 147-166, 2006.

25. Smeraldi E, Zanardi R, Benedetti F, et al: Polymorphism within the promoter of the serotonin transporter gene and antidepressant efficacy of fluvoxamine. Mol Psychiatry 3: 508-511, 1998.

26. Guscott M, Bristow LJ, Hadingham K, et al: Genetic knockout and pharmacological blockade studies of the 5-HT7 receptor suggest therapeutic potential in depression. Neuropharmacology 48 : 492-502, 2005

27. Watanabe MA, Nunes SO, Amarante MK, et al: Genetic polymorphism of serotonin transporter 5-HTTLPR: involvement in smoking behaviour. J Genet 90: 179-185, 2011.

28. Hoefgen B, Schulze TG, Ohlraun S, et al: The power of sample size and homogenous sampling: association between the 5-HTTLPR serotonin transporter polymorphism and major depressive disorder. Biological Psychiatry 57: 247-251, 2005. 
29. Nobile M, Cataldo MG, Giorda R, et al: A case-control and family-based association study of the 5-HTTLPR in pediatric-onset depressive disorders. Biol Psychiatry 56: 292-295, 2004.

30. Gonda X, Juhasz G, et al: Subthreshold depression is linked to the functional polymorphism of the 5HTtransporter gene. J Affect Disord 87: 291-297, 2005.

31. Zhang K, Xu Q, Xu Y, et al: The combined effects of the 5-HTTLPR and 5-HTR1A genes modulates the relationship between negative life events and major depressive disorder in a Chinese population. J Affect Disord 114: 224-231, 2009.

32. Hemmati S, Kahrizi K, Najmabadi H and Sahrawian S: Analysis of association serotonin transporter gene and antidepressant response to citalopram in iranian major depressive population. European Psychiatry 27: 1, 2012.

33. Cervilla JA, Molina E, Rivera M, et al; PREDICT Study Core Group: The risk for depression conferred by stressful life events is modified by variation at the serotonin transporter 5HTTLPR genotype: evidence from the Spanish PREDICT-Gene cohort. Mol Psychiatry 12: 748-755, 2007.
34. Steffens DC, Svenson I, Marchuk DA, et al: Allelic differences in the serotonin transporter-linked polymorphic region in geriatric depression. Am J Geriatr Psychiatry 10: 185-191, 2002.

35. Clarke H,Flint J, Attwood AS and Munafò MR: Association of the 5-HTTLPR genotype and unipolar depression: a meta-analysis. Psychol Med 40: 1767-1778, 2010.

36. Furlong RA, Ho L, Walsh C, et al: Analysis and meta-analysis of two serotonin transporter gene polymorphisms in bipolar and unipolar affective disorders. Am J Med Genet 81: 58-63, 1998.

37. Minov C, Baghai TC, Schüle C, et al: Serotonin-2A-receptor and -transporter polymorphisms: lack of association in patients with major depression. Neurosci Lett 303: 119-122, 2001.

38. Xia DS, Guo QY, Liu YQ, et al: Association of serotonin transporter gene linked polymorphic region polymorphism with early onset myocardial infarction and platelet membrane glycoprotein I b. Zhonghua Yi Xue Yi Chuan Xue Za Zhi 26: 31-34, 2009 (In Chinese).

39. Shen Y, Li H, Gu N, et al: Relationship between suicidal behavior of psychotic inpatients and serotonin transporter gene in Han Chinese. Neurosci Lett 372: 94-98, 2004. 